\title{
Juventude e Violência: $O$ que Pensam os Jovens de um Projovem Urbano em Natal/RN
}

\author{
Arthemis Nuamma Nunes de Almeida ${ }^{1}$ \\ Programa de Pós-Graduação em Psicologia da Universidade Federal do Rio Grande \\ do Norte, Natal, Rio Grande do Norte, Brasil \\ Caroline Cristina de Arruda Campos \\ Instituto Federal de Educação, Ciência e Tecnologia do Rio Grande do Norte, \\ João Câmara, Rio Grande do Norte, Brasil \\ Luana Isabelle Cabral dos Santos \\ Programa de Pós-Graduação em Psicologia da Universidade Federal do Rio Grande \\ do Norte, Natal, Rio Grande do Norte, Brasil \\ Ilana Lemos de Paiva \\ Departamento de Psicologia da Universidade Federal do Rio Grande do Norte, Natal, \\ Rio Grande do Norte, Brasil
}

\section{Resumo}

A juventude tem ganhado mais espaço na mídia, nas pesquisas acadêmicas e nos debates públicos, especialmente, por ser um grupo social que vivencia diversos contextos de vulnerabilidade. Em resposta às situações adversas que permeiam a vida dos jovens, tem-se a criação do Programa Nacional de Inclusão de Jovens (Projovem) que, em 2008, passa a ser executado a partir de quatro modalidades (Adolescente, Urbano, Trabalhador e Campo). Tal pesquisa aconteceu na modalidade Projovem Urbano (PJU) e objetivou analisar a relação juventude-violência, a partir do ponto de vista dos jovens, e a contribuição do PJU para essa questão. Foram realizadas onze entrevistas semiestruturadas com os jovens do PJU, bem como a análise documental da sua estrutura curricular. Esses dados foram analisados a partir do Método Comparativo Constante (MCC), baseado na Teoria Fundamentada, que busca compreender o fenômeno sob a perspectiva dos participantes. Os resultados demonstraram que o tema da violência aparece frequentemente na fala dos jovens sob a forma de exemplos e indicações de possíveis determinantes, e também que os jovens se configuram como autores, vítimas e expectadores da violência. A respeito da contribuição do PJU, percebe-se que o programa contempla em seu currículo a temática da violência, embora as discussões e debates não alcancem todos os jovens participantes. Conclui-se que o PJU deve avançar no sentido de investigar seus efeitos para os jovens e melhor definir o método de operacionalização do currículo, contribuindo para redimensionar as possibilidades de mudanças e construção de novos projetos de vida para os jovens usuários.

Palavras-chave: Projovem urbano, juventude, violência, política pública.

1 Endereço para correspondência: Rua Alvorada, 566, Igapó, Natal, RN, Brasil, 59104-210. E-mail: arthemisnuamma7@gmail.com, carolarrudacampos@gmail.com, luanaicsantos@gmail.com e ilanapaiva@hotmail.com Agência de financiamento: Programa de Bolsas de Iniciação Científica da Pró-Reitoria de Pesquisa e Pós-Graduação (PROPESQ - REUNI). 


\title{
Youth and Violence: What the Youngster from Natals Urban Projovem Think
}

\begin{abstract}
The youth has acquired more space among the media, academic researches and political debates, especially because it concerns to a social group which go through several contexts of vulnerability. In order to contribute with the solutions for the adversities faced by the youngsters, the Programa Nacional de Inclusão de Jovens (Projovem) has been created and, in 2008, was implemented into four modalities "Adolescente", "Urbano", "Trabalhador" and "Campo". This research has focused on Projovem Urbano (PJU) and aimed to analyze the relation Youth-Violence from the youngsters' points of view and the contribution of PJU to this question. Eleven semi-structured interviews with the PJU youngsters and a documental analysis of the curriculum structure of the Program have been accomplished. The collected data has been analyzed through the Constant Comparative Method, based on the Grounded Theory, which seeks to understand the phenomena from the perspective of the participants. The results have revealed that the violence issue is often part of the youngsters' speeches, through examples and determinant indications, and, have shown that youngsters are agents, victims and spectators of the violence. Concerning to the contribution of PJU, the Program states on its curriculum the violence theme, although the discussions and debates do not reach all the involved participants. It's possible to conclude that PJU must advance into the investigation of its effects among the youngsters and into the definition improvement of its curriculum operationalization method by contributing to remodel the possibilities of changes and the construction of new life projects for the youth.
\end{abstract}

Keywords: Projovem urbano, youth, violence, public policy.

\section{Juventud y Violencia: Lo que Piensan los Jóvenes de un Projoven Urbano en Natal/RN}

\section{Resumen}

La juventud ha ganado más atención en los medios de comunicación, investigación académica y debates públicos, especialmente por ser un grupo social que experimenta diferentes contextos de vulnerabilidad. En respuesta, ha sido creado el Programa Nacional de Inclusión de Jóvenes (Projoven) y, en 2008, está a cargo de cuatro modalidades (Adolescente, Urbano, Trabajo y Campo). Esta investigación se detuve en el Projoven Urbano (PJU) y tuvo como objetivo analizar la relación entre jóvenes-violencia, desde el punto de vista de los jóvenes, y la contribución del PJU para este problema. Se realizaron once entrevistas semiestructuradas con jóvenes del programa, así como el análisis de su estructura curricular. Los datos se analizaron desde el Método Comparativo Constante (MCC), basado en la Teoría Fundamentada, que busca entender el fenómeno desde la perspectiva de los participantes. Los resultados mostraron que la cuestión de la violencia frecuentemente aparece en el discurso en forma de ejemplos e indicaciones de posibles determinantes, y también que los jóvenes se caracterizan por ser los autores, las víctimas y los testigos de la violencia. En cuanto a la contribución del programa PJU, se ha percibido que el programa incluye en sus contenidos el tema de la violencia, aunque las discusiones y debates que no llegan a todos los jóvenes participantes. Se concluye que el PJU debe investigar sus efectos sobre los jóvenes y definir mejor el método de funcionamiento de sus contenidos, contribuyendo ampliar las posibilidades de cambio y los nuevos proyectos de vida para los jóvenes usuários.

Palabras clave: Projoven urbano, juventude, violência, política pública. 
A juventude tem ganhado cada vez mais espaço na mídia, nas pesquisas acadêmicas e nos debates públicos (Lino et al., 2007). Esse espaço tem sido conquistado, principalmente, a partir do processo de redemocratização do país que anuncia, por meio da sua carta constitucional e do Estatuto da Criança Adolescente (ECA), uma maior preocupação e interesse com o público jovem.

Considerada uma etapa da vida - e não uma mera fase de transição - a Juventude carrega sentido em si mesma. É nessa etapa que o indivíduo processa de maneira mais intensa a conformação de sua trajetória, valores, e a busca de sua plena inserção na vida social, bem como também existe uma maior energia e potencial para o engajamento (Ministério do Planejamento, Orçamento e Gestão, 2011).

Embora se percebam características comuns aos jovens durante esta etapa geracional, a vivência da juventude para alguns é diferenciada, especialmente, a partir de certos elementos. Assim, em virtude da diversidade de situações socioeconômicas e culturais que afetam os indivíduos nessa etapa do ciclo de vida, tem sido recorrente a importância de se tomar a ideia de juventude em seu sentido plural: juventudes (Sposito, 2003). Reconhecer que a experiência da juventude não acontece da mesma maneira para todos os jovens é o primeiro passo para compreendermos melhor os processos e questões que perpassam suas vidas.

Atualmente, no Brasil, a Secretaria Nacional de Juventude delimita esse período na faixa etária situada dos 15 aos 29 anos, que é a adotada, inclusive, no Estatuto da Juventude. No entanto, não existe consenso na demarcação dessa faixa etária, nem tampouco um único conceito para juventude, justamente por entender esse período como algo dinâmico, histórico, processual, e, em permanente construção com variações temporais, culturais e sociais (Aquino, 2009).

Para além dessas questões conceituais, a pauta da juventude é um assunto que se coloca como sendo um dos mais importantes dentre os diversos problemas e questões cruciais que são desafios às políticas de desenvolvimento social na América Latina. $\mathrm{O}$ expressivo contingente de jovens existentes, principalmente quando com- parado à população em geral, somado ao aumento da violência, da pobreza e a diminuição das oportunidades de emprego estão deixando a juventude latino-americana sem perspectivas para o futuro. As dificuldades se tornam maiores, especialmente, para a juventude que enfrenta situações sociais adversas com pouca ou nenhuma cobertura das suas necessidades mínimas, o que dificulta uma participação ativa no processo de conquista da cidadania (Abramovay, Castro, Pinheiro, Lima, \& Martinelli, 2002).

Considerar as diversas questões que perpassam os problemas sociais, os quais atingem diretamente a parcela jovem da população, é compreender como se dão as relações no nosso mundo contemporâneo, caracterizado por um tempo que combina um acelerado processo de globalização com a manutenção das desigualdades sociais. Novaes (2007) colabora com a discussão acrescentando que:

pelo mundo afora, são os jovens os mais atingidos: tanto pelas transformações sociais, que tornam o mercado de trabalho restritivo e mutante, quanto pelas distintas formas de violência física e simbólica, que caracterizaram o final do século XX e persistem neste início do século XXI. (p. 253)

Outra categoria de análise adotada nesse artigo, e que se faz necessário discutir, é a violência. De acordo com Gonçalves (2003), a violência é complexa, polissêmica e controversa, sendo sua definição um desafio que não se restringe a simples descrição, nem ao entendimento imediato. Por princípio, ela é ambígua. Ou seja, não existe uma única percepção, mas multiplicidade de atos violentos, cujos significados devem ser analisados levando-se em conta as normas, condições e contextos sociais, com variações de um período histórico a outro (Abramovay et al., 2002). Assim, Peres, Ruotti e Vicentin (2010) afirmam que a violência é um fenômeno social e histórico que, por isso mesmo, torna-se fluído e diversificado.

Embora seja considerada como um conceito em permanente mutação, uma vez que várias atitudes e comportamentos passaram a ser considerados como formas de violência, pode-se concebê-la como "um fenômeno multifacetado, 
que não somente atinge a integridade física, mas também as integridades psíquicas, emocionais e simbólicas de indivíduos ou grupos nas diversas esferas sociais, seja no espaço público, seja no espaço privado" (Abramovay et al., 2002, p. 27).

Para entender esse fenômeno é preciso não somente o conhecimento dos fatos, mas das representações que se tem da violência, ou seja, deve-se considerar como os sujeitos a percebem em suas realidades (Peres et al., 2010). Outro ponto a ser considerado sobre esse complexo fenômeno social é que não se restringe a determinados nichos sociais, raciais, econômicos e/ ou geográficos. Entretanto, a violência pode ser vivenciada de forma distinta e acentuada nas diferentes classes sociais, idades, gêneros, e, etnias, tanto na condição de vítima como de agentes agressores (Abramovay et al., 2002).

$O$ enfoque na vulnerabilidade social, entendida como "o resultado negativo da relação entre a disponibilidade dos recursos materiais ou simbólicos dos atores, sejam eles indivíduos ou grupos, e o acesso à estrutura de oportunidades sociais, econômicas, culturais que provêm do Estado, do mercado e da sociedade" (Abramovay et al., 2002, p. 13), se constitui em ferramenta valiosa para compreender a situação da juventude e da sua relação com a violência. Segundo Fachinetto (2010), essas múltiplas vulnerabilidades, que atingem de formas diferenciadas a juventude, devem ser entendidas como as constantes violações dos direitos dos jovens, pois, mesmo que sejam legalmente considerados como sujeitos de direitos, na prática há ainda um largo caminho a percorrer.

Para se ter uma ideia do grau de vulnerabilidade no qual os jovens estão inseridos, de acordo com dados do Instituto Brasileiro de Geografia e Estatística (IBGE, 2012), a população entre 15 e 24 anos no Brasil, em 2011, somou 78,5 milhões, o que equivale a $40,2 \%$ da população em geral. Porém, esses dados não contemplam a faixa etária que vai dos 25 aos 29 anos, fazendo com que esse número seja ainda maior.

Ao se direcionar uma atenção mais criteriosa para os índices de homicídios em nosso país, é possível perceber uma conjuntura em que a cultura da violência somada à falta de investi- mento na juventude constituem-se como fatores que impactam diretamente os números. Tem-se, então, os elementos para a constituição de um contexto em que os jovens são as maiores vítimas, sobretudo homens e, mais ainda, negros. De acordo com Penna e Neto (2010), os diferentes tipos de violência representam a terceira causa de morte na população em geral, situação que se agrava quando se observa o grupo etário que contempla a faixa de 01 a 39 anos, em que é a primeira causa de morte.

De modo geral, a população jovem é o grupo mais afetado pelos homicídios, cerca de $39,3 \%$, enquanto que esse índice na população não jovem é de $3 \%$. Se forem adicionadas outras situações que levam à morte da juventude - consideradas causas externas, como os acidentes de trânsito -, esse índice cresce para 73,2\%. Trazendo a reflexão para o contexto local, de acordo com dados do Mapa da Violência, no estado do Rio Grande do Norte (RN), a porcentagem de mortes por causas externas é de 77,6\% - perdendo apenas para o estado de Alagoas (83,1\%), na região Nordeste. Considerando o período de 2001-2011, a porcentagem de jovens mortos por causas externas aumentou $313 \%$, elevando-se de 99 homicídios, em 2001, para 409, em 2011 (Waiselfisz, 2013).

Uma análise sobre esse considerável e histórico aumento no número de homicídios na faixa etária da juventude conduz a pensar sobre algumas questões. Um primeiro ponto é o fato de que os jovens estão sujeitos a uma série de fatores - precarização do trabalho, evasão escolar, envolvimento com substâncias ilícitas, etc que acabam vulnerabilizando-os e vitimando-os e que não estão presentes de forma tão extrema nas outras faixas etárias, pois, a diferença nos percentuais de homicídios entre a juventude e as demais faixas é significativa (Waiselfisz, 2013). Outra questão se refere à ausência de perspectivas de futuro, levando uma parte desse segmento a se inserir na criminalidade em suas mais variadas facetas, do narcotráfico ao cometimento de roubos e outras infrações, deixando essa juventude ainda mais vulnerável à violência.

Se, por um lado, os jovens são o segmento social mais vitimado pela violência, como se 
observa nos dados supracitados, por outro, eles também se configuram como autores. É a violência que se manifesta por meio de:

atos de delinquência corriqueiros, o vandalismo contra o espaço público, nos rachas e nas manobras radicais no trânsito, nas brigas entre gangues rivais, no dia a dia do ambiente escolar ou nas agressões intolerantes a homossexuais, negros, mulheres, nordestinos ou índios em várias partes do país é majoritariamente protagonizada por jovens e, em geral, vitima outros jovens. (Ferreira, Fontoura, Aquino, \& Campos, 2009, pp. 200-201)

Pode-se perceber, através do subsídio dos índices de homicídios contra jovens, que a violência se caracteriza como uma forma de se relacionar, a qual muitas vezes é naturalizada, valorizada e até justificada pela sociedade brasileira. Nas relações cotidianas, a população enfrenta diversos tipos de situações conflitivas, no entanto, o modo encontrado pelas pessoas para buscar resolver seus interesses e lidar com seus problemas, muitas vezes, é através do uso de recursos violentos, o que contribui para manter um ciclo de violência que necessita, mais do que nunca, ser rompido.

Por tudo isso, pensar os contextos de vulnerabilidade social em que os jovens estão inseridos e suas relações com as diversas formas de violência, expressa a necessidade do desenvolvimento de políticas públicas específicas para esse segmento (Ministério do Planejamento, Orçamento e Gestão, 2011).

Parte-se do entendimento de Políticas Públicas como as ações que o Estado determina, a partir das necessidades e demandas da sociedade. Também as compreende como uma arena de conflitos e disputas, o que justifica o fato delas possuírem tanto aspectos negativos quanto positivos, sendo contraditórias e complexas. Nesse sentido, política pública é uma ação pública, que envolve tanto o Estado - enquanto interventor e mediador - quanto à sociedade, visando o bem coletivo (Pereira, 2008). Especificamente, sobre as políticas públicas voltadas para/de/com a juventude, elas podem indicar o modo como os jovens são entendidos na sociedade e a forma dominante de como esse segmento é concebido, nesse aspecto, as políticas podem agir ativamente, produzindo novas formas de se conceber a juventude (Sposito \& Carrano, 2003).

Observa-se que se começa a ter um maior investimento nas políticas de juventude por volta dos anos 1990 e início dos anos 2000, pois, as problemáticas dos jovens deixam de ser apenas um "estado de coisas" e ganham status de problema político, necessitando de intervenções. E, nesse aspecto, uma série de iniciativas são pensadas e postas em prática pelo poder público e sociedade civil. Assim, paulatinamente, os jovens vão sendo vistos enquanto sujeitos de direitos (Novaes, 2009), reconhecendo-se, assim, as suas demandas como legítimas.

Em 2004 é instituído um grupo interministerial, sob a coordenação da Secretaria Geral da Presidência da República, que realiza um diagnóstico da situação juvenil no país e um mapeamento das ações que são voltadas para a juventude (Salgado \& Jardim, 2010). Já em 2005, são criadas: a Secretaria Nacional de Juventude (SNJ), o Conselho Nacional de Juventude (CONJUVE) e o Programa Nacional de Inclusão de Jovens (Projovem), de caráter emergencial e experimental, constituindo, assim, o tripé da Política Nacional de Juventude (PNJ; Silva \& Andrade, 2009).

Em 2007, o Projovem passa por uma avaliação e reformulação, visando melhorias na atenção à juventude e também à expansão da cobertura. Em 2008, tem-se a união de alguns programas já existentes e a articulação deles no chamado Projovem Integrado, que passa a ser executado a partir de quatro modalidades: Projovem Adolescente - serviço socioeducativo, Projovem Urbano, Projovem Campo - saberes da terra, e Projovem Trabalhador (Silva \& Andrade, 2009).

O presente artigo versará especificamente sobre o Projovem Urbano (PJU), modalidade em que se realizou a pesquisa. O PJU atende a um público de jovens na faixa etária entre 18 e 29 anos, que não tenham concluído o ensino fundamental, mas que saibam ler e escrever e que sejam membros de famílias com renda mensal per capita de até meio salário mínimo (SM; Silva 
\& Andrade, 2009). A modalidade oferece uma bolsa no valor de R $\$ 100,00$ reais, durante os 18 meses de funcionamento (divididos em três ciclos de seis meses cada), desde que o jovem esteja com a frequência e as atividades em dia.

O Projeto do PJU integra três eixos de formação: educação, qualificação profissional e participação comunitária, articulando diferentes esferas da vida dos jovens. A estrutura do projeto pedagógico se organiza em torno de ciclos, os quais são compostos por unidades formativas, totalizando uma carga horária de 2000 horas, sendo 1560 horas presenciais e 440 horas não presenciais (Salgado \& Jardim, 2010).

Assim, objetiva-se analisar como a relação juventude-violência é vivenciada pelos jovens participantes de um Projovem Urbano no município de Natal/RN. Especificamente, busca-se discutir, sempre a partir da percepção dos jovens participantes, quais os determinantes da violência, se existem ações do Projovem Urbano relacionadas ao enfrentamento da violência e se essas ações se coadunam com as propostas do Programa.

\section{Método}

Esta pesquisa se vincula aos trabalhos do núcleo de Políticas Públicas de Juventude, que, por sua vez, faz parte do Observatório da População Infanto-Juvenil em Contextos de Violência (OBIJUV) - projeto de pesquisa e extensão vinculado à Universidade Federal do Rio Grande do Norte (UFRN).

\section{Participantes}

Participaram da investigação onze jovens de um núcleo do Projovem Urbano (PJU) da cidade de Natal/RN. O PJU que foi campo de pesquisa se localizava no distrito Norte da cidade, região essa que possui altos índices de vulnerabilidade social.

\section{Instrumentos}

Para a efetivação dos objetivos de pesquisa, realizaram-se entrevistas semiestruturadas e análise documental da estrutura curricular do
Projovem Urbano, para complementar as informações. Estruturalmente, a entrevista se subdividiu em três blocos, a saber: (a) dados sociodemográficos; (b) percepção sobre o Projovem; e, (c) juventude, violência e Projovem, que abrangeu a percepção do jovem a respeito: da violência, da relação violência-juventude, como avaliam o envolvimento dos jovens em atos de violência, como o Projovem trata o tema da violência, qual sua importância, e quais as contribuições do programa para reduzir a violência no bairro.

\section{Procedimentos de Coleta de Dados}

Para a coleta de dados foi realizado um contato prévio com o núcleo para exposição dos objetivos e importância da pesquisa e entregou-se um ofício do OBIJUV/UFRN explicitando tais informações, para ciência e registro. Após esse momento, as pesquisadoras foram apresentadas aos professores em suas salas de aula, e, com isso, os jovens usuários também as conheceram. Esse momento foi importante porque quando os mesmos foram convocados a participar, já conheciam, minimamente, a pesquisa. Os entrevistados foram escolhidos por indicação dos professores, compondo uma amostra por saturação e as entrevistas aconteceram nas próprias salas de aula (após o turno) ou na sala dos professores.

\section{Procedimentos de Análise de Dados}

Para a análise do corpus da pesquisa utilizou-se o Método Comparativo Constante (MCC), baseado na Teoria Fundamentada nos Dados (Grounded Theory), que possibilita a criação de categorias, após a coleta dos dados. A preocupação central da Teoria Fundamentada nos Dados é descobrir a informação que é relevante para o problema estudado e, nesse sentido, o objetivo principal não é a descrição da realidade, mas sim, uma explicação, a partir da interpretação das falas dos entrevistados (Trinidad, Carrero, \& Soriano, 2006).

O MCC apresenta quatro etapas, as quais sejam: (a) comparação de incidentes e sua categorização; (b) integração de categorias e propriedades; (c) conceitualização teórica e; (d) escrita 
do documento final. Essas etapas fazem com que o pesquisador, desde o início do processo, reflita sobre as informações que estão sendo coletadas (Trinidad et al., 2006).

Para auxiliar a organização dos dados e elaboração das categorias de análise, utilizou-se o software de análise de dados qualitativos QDA MINER versão 4. Após a construção das categorias de análise, estas foram agrupadas em três blocos, a saber: caracterização dos usuários, relação juventude-violência, e, Projovem Urbano como estratégia de enfrentamento à violência juvenil.

\section{Procedimentos Éticos}

As entrevistas foram gravadas em equipamento de áudio para garantir legitimidade das falas, e, para tanto, houve assinatura do Termo de Consentimento Livre e Esclarecido (TCLE) pelos participantes para assegurar a confidencialidade e demais cuidados éticos. Além disso, primou-se pelo sigilo das informações. Por fim, foram utilizados nomes fictícios para preservar a identidade dos participantes e obedecer aos cuidados éticos.

\section{Resultados e Discussão}

\section{Caracterização dos Usuários}

A partir do levantamento dos dados sociodemográficos dos jovens participantes do PJU, como se observa na Tabela 1 , pode-se perceber que, em geral, os alunos que entraram no Projovem Urbano passaram, no mínimo, dois anos longe dos bancos escolares. No entanto, duas pessoas da amostra entrevistada relataram não ter parado de estudar. Este fato em si já se caracteriza como um importante dado para a problematização do sistema educacional brasileiro, uma vez que o público alvo do Projovem Urbano é composto por jovens de 18 a 29 anos os quais não tenham concluído o ensino fundamental. $\mathrm{Na}$ amostra, também chama a atenção o fato de ter jovens participantes que nunca interromperam seus estudos e, ao completarem 18 anos, ainda estão no ensino fundamental, o que os caracteriza como usuários do PJU. Isso demonstra que mesmo não se afastando da escola, alguns jovens vivenciam uma grande distorção entre idade-série, o que pode indicar uma vivência de constante "reprovações" na vida escolar.

Tabela 1

Dados Sociodemográficos dos Jovens Usuários do Núcleo do PJU Investigado

\begin{tabular}{|c|c|c|c|c|c|c|c|c|}
\hline Caso & Idade & Sexo & Escolaridade & $\begin{array}{l}\mathrm{N}^{\mathrm{o}} \text { de } \\
\text { Filhos }\end{array}$ & $\begin{array}{l}\text { Renda } \\
\text { Familiar }\end{array}$ & $\begin{array}{l}\text { Ativ. } \\
\text { Rem. }\end{array}$ & $\begin{array}{c}\text { Estado } \\
\text { Civil }\end{array}$ & $\begin{array}{c}\text { Ano em que parou } \\
\text { de estudar }\end{array}$ \\
\hline Luiz & 19 & M & $7^{\circ}$ ano & 0 & $\cong 300,00$ & Sim & Solteiro & Não parou \\
\hline Paulo & 26 & M & $7^{\circ}$ ano & 0 & $1.500,00$ & Sim & Solteiro & 2002 \\
\hline José & 24 & M & $7^{\circ}$ ano & 1 & $\cong 900,00$ & Sim & Solteiro & 2003 \\
\hline Maria & 22 & $\mathrm{~F}$ & $7^{\circ}$ ano & 1 & Não sabe & Sim & Solteira & 2006 \\
\hline Laura & 25 & $\mathrm{~F}$ & $5^{\circ}$ ano & 3 & Mais de um SM & Não & Casada & 2002 \\
\hline Sandra & 29 & $\mathrm{~F}$ & $9^{\circ}$ ano & 2 & $1.500,00$ & Sim & Solteira & Não parou \\
\hline Patrícia & 20 & $\mathrm{~F}$ & $8^{\circ}$ ano & 1 & 700,00 & Sim & Solteira & 2007 \\
\hline Ana & 26 & $\mathrm{~F}$ & $9^{\circ}$ ano & 1 & $\cong 700,00$ & Sim & Solteira & 2004 \\
\hline Pedro & 26 & M & $5^{\circ}$ ano & 1 & $1.300,00$ & Sim & Solteiro & 2005 \\
\hline Clara & 24 & $\mathrm{~F}$ & $6^{\circ}$ ano & 2 & 223,00 & Sim & Solteira & 2006 \\
\hline Bruna & 26 & $\mathrm{~F}$ & $\begin{array}{c}2^{a} \text { Série do } \\
\text { Ensino Médio }\end{array}$ & 1 & 400,00 & Não & Solteira & 2009 \\
\hline
\end{tabular}


A situação de defasagem escolar é apontada na síntese dos indicadores sociais da população brasileira, em que mesmo havendo um aumento da frequência líquida à escola, de uma maneira geral, na faixa etária de 15 a 17 anos, esse aumento esconde os efeitos da defasagem idade-série, isto é, do atraso escolar proveniente dos níveis educacionais anteriores. Além disso, como consequência do atraso escolar, somente metade destes jovens, entre 15 e 17 anos, frequentava o ensino médio no ano de 2011 (IBGE, 2012).

Outro ponto, é que cerca de metade dos jovens estudantes, de 18 a 24 anos de idade, que já deveriam ter completado suas trajetórias escolares na educação básica e avançado para o ingresso no ensino superior não conseguiram realizar essa trajetória (IBGE, 2012). Essa realidade também se aplica aos participantes da pesquisa, pois, grande parte deles parou de estudar no $7^{\circ}$ ano do ensino fundamental, antes de entrar no Projovem Urbano, e permaneceram afastados da escola por, no mínimo, dois anos.

Diversos são os motivos que levam à evasão dos jovens do ambiente escolar. Na pesquisa em questão, os motivos para esse afastamento da escola giraram em torno de: gravidez, trabalho, mudança de cidade e consumo de drogas. Em relação ao trabalho, especificamente, os jovens relataram já ter exercido alguma atividade remunerada, as quais se configuraram nas atividades de: vendedor, segurança, recepcionista, auxiliar de serviços gerais (ASG), representante de vendas, pintor e costureira.

Destaca-se, assim, a importância do trabatho no conjunto do rendimento familiar, especialmente no tocante à provisão de bem-estar e manutenção no padrão de vida. A partir da análise da síntese dos indicadores sociais da população brasileira (IBGE, 2012), no período compreendido entre 2001-2011, a proporção de pessoas de 16 anos de idade, ou mais, trabalhando em empregos formais obteve um aumento de 10,7 pontos percentuais. O país, entretanto, continua registrando um contingente expressivo de sua mão de obra (masculina e feminina) em trabalhos informais: 44,2 milhões de pessoas. Isso é corroborado pelos entrevistados, que embora já tenham exercido ou exerçam alguma atividade remunerada, possuem ocupações, muitas vezes, pertencentes ao mercado informal de trabalho, como: costureira, realização de "bicos" de pintor, revendedor de produtos de revistas, etc.

Em relação a outros elementos da tabela, percebe-se uma convergência com o perfil nacional dos jovens atendidos pelo programa: o referido perfil avaliou que $53 \%$ dos usuários são do sexo feminino e, que, no geral, $77,5 \%$ são solteiros (Salgado, 2008). Essa realidade não diverge da presente amostra, em que a maioria é do sexo feminino, e, somente uma pessoa é casada.

Por fim, no que concerne à vida familiar e número de filhos, dois entrevistados mencionaram não possuir, entretanto, os que mencionaram (nove entrevistados) tem de um a dois filhos, e uma jovem tem três filhos. Isso parece demonstrar a fundamental importância da compreensão da forma como se organizam e atuam os núcleos familiares para se estudar as condições sociais da população e analisar diferentes aspectos de suas vidas: comportamento demográfico, a participação no mercado de trabalho, a distribuição de renda, os padrões de consumo e de gastos, a mobilidade social, etc. (IBGE, 2012).

Pode-se perceber, portanto, que os jovens participantes da pesquisa se encontram em uma realidade sociodemográfica bem próxima da população nacional atendida pelo programa (Santos, 2013). O que parece apontar, de fato, que esses jovens precisam que as políticas públicas a eles destinadas possam buscar a transformação em suas realidades, especialmente nos campos educacionais e de trabalho e emprego, em que os índices são muito aquém do ideal.

\section{Relação Juventude-Violência}

Esse bloco diz respeito à percepção que os jovens têm sobre o que é violência, seus principais determinantes, e a relação entre ser jovem e a violência.

Percepção dos Jovens Sobre a Violência. Esse primeiro eixo busca discutir qual a percepção do jovem sobre o que seria a violência. Segundo Lopes et al. (2008) os significados da violência explicitam uma diversidade de defini- 
ções e representações, tornando difícil sua caracterização sob uma única ótica - dada a sua natureza como fenômeno complexo e multideterminado. De fato, é um conceito que abrange significados e circunstâncias muito diversas. As suas manifestações são igualmente múltiplas, podendo assumir naturezas tanto visíveis e concretas, como invisíveis e sutis. Isso dialoga com a ideia de que a violência possui muitas causas e que por trás de uma ação violenta estão envolvidos vários fatores de naturezas diversas.

Com relação à fala dos participantes sobre qual seria o conceito de violência, verificou-se, durante a pesquisa, que os jovens entrevistados tiveram dificuldades em defini-la. Acredita-se que essa dificuldade seja reflexo da complexidade desse fenômeno social. Assim, as respostas dos entrevistados sobre definição de violência abordaram diversos exemplos, indicando formas em que esse fenômeno se revela, e, as quais foram agrupadas em dois conjuntos: agressão física (estupro, homem bater em mulher, bater em criança, espancar, homicídio, assalto e brigar) e agressão verbal (julgar, humilhar, falar mal e falta de respeito).

Diversas organizações, como a Organização das Nações Unidas para a Educação, a Ciência e a Cultura (UNESCO) utilizam três denominações - direta, indireta, e simbólica - para identificar as diferentes expressões do fenômeno da violência. A violência direta diz respeito aos atos físicos que resultam em prejuízo à integridade da vida humana, envolve todas as modalidades de homicídios. Já a violência indireta consiste em todos os tipos de ação coercitiva ou agressiva que causem prejuízo psicológico ou emocional. Por fim, a violência simbólica envolve as relações de poder interpessoais ou institucionais que intervêm na livre ação, pensamento e consciência dos indivíduos (Abramovay et al., 2002). Nesse sentido, foi possível visualizar que os três tipos de denominações citadas acontecem e estão presentes na realidade dos jovens do PJU, indicando como esse fenômeno é pulverizado e se expressa em diversos contextos e com diferentes determinantes.

Determinantes da Violência. O contexto de violência e violação de direitos e as altas taxas de homicídios na juventude tem relação direta com alguns fatores, tais como: preconceito, a falta de tolerância, a falta de respeito à diversidade, o medo do diferente, a ausência de espaços de convivência e de uma cultura de diálogo e mediação, além da valorização pela mídia de determinados símbolos, comportamentos e atitudes (Rechenberg \& Zagallo, 2010).

Esse eixo visa discutir os determinantes da violência a partir das falas dos jovens entrevistados, ou seja, quais as suas percepções sobre os elementos que possibilitam a produção desse fenômeno social ou a ele estão associados. Com isso, os entrevistados apontaram elementos como: o preconceito, o consumo e tráfico de drogas (lícitas e ilícitas), os contextos socioeconômicos (pobreza, amizades, moradia, falta de educação e de respeito, a falta de ocupação e problemas familiares), o ciclo de reprodução da violência (em que o jovem pratica porque sofreu antes), alguns determinantes internos (impulso) e a criminalidade.

De acordo com Abramovay et al. (2002), nas grandes cidades da América Latina e Caribe, em relação às diferentes formas de violência que atuam entre seus habitantes, incidem fatores individuais, familiares, sociais e culturais afetando a conduta doméstica e social. Por isso, mais uma vez convém examinar a violência a partir de um enfoque multicausal.

Um dos determinantes da violência que emerge na fala dos jovens é o preconceito. A noção de preconceito está intimamente ligada à noção de discriminação, em que são adotadas atitudes, muitas vezes negativas e pejorativas, por uma pessoa (ou grupo) em relação à outra pessoa (ou grupo). A relação entre preconceito e violência assinalada pelos participantes da pesquisa aponta indícios para se compreender a realidade vivenciada pela juventude brasileira.

Foram recorrentemente citados pelos jovens, também, o consumo de drogas e as diversas relações com o tráfico como determinantes de situações de violência. Essa relação está presente no discurso dos participantes, como exemplificam os trechos de entrevista a seguir: "acho que o pessoal . . . depois de usar drogas, acho que fica violento mesmo" (Luiz), e, "tem muito jovem 
envolvido em meio de droga, mata pra sustentar o vício, rouba, essas coisas assim . . . o começo de tudo tá nas drogas" (Laura). Essa relação entre drogas e violência pode existir, entretanto, é "uma articulação complexa, pouco analisada, cujos únicos parâmetros para afirmações, na atualidade, são apenas os de associação empírica" (Minayo \& Deslandes, 1998, p. 36).

Conforme Minayo e Deslandes (1998), vários estudiosos concluíram que o álcool é a substância mais ligada às mudanças de comportamento e que resulta em violência em função de efeitos psicofarmacológicos. Tal fato foi exposto pelos jovens nas entrevistas, como: "de beber, deles beberem e praticar violência" (Clara). Ainda conforme as autoras supracitadas, há evidências de que drogas como a cocaína, as anfetaminas e os esteróides têm propriedades que podem motivar atitudes, comportamentos e ações violentas. No entanto, não há uma certeza quanto às explicações causais. Além disso, alguns fatores levam à diferenças individuais $\mathrm{e}$ mudança de comportamento quando do uso de drogas, como: peso corporal, tipo de metabolismo, processos neuroendócrinos e neuroanatômicos. Fatores socioculturais e de personalidade também tem contribuição - o que pode sugerir que a violência interpessoal que ocorre sob o efeito de substâncias é contextualizada.

É interessante considerar a costumeira associação entre drogas e violência num contexto da ilegalidade e da criminalidade, ou seja, o crime é visto como uma fonte de recursos para a compra de drogas, como cocaína, crack e heroína. Além disso, ações violentas entre vendedores e compradores acontecem sob uma quantidade enorme de pretextos: "roubo do dinheiro ou da própria droga, disputas em relação a sua qualidade ou quantidade, desacordo de preço, disputa de territórios" (Minayo \& Deslandes, 1998, p. 37). Entretanto, a motivação econômica é apenas uma explicação parcial para o complexo universo que é o mercado de drogas ilícitas.

Os jovens ainda apontaram, durante as entrevistas, que a prática da violência estava condicionada ao fato de ela ter ocorrido primeiro ao indivíduo, e, ele reagiria por defesa própria, ou ainda, por revanche. Alguns trechos exem- plificam a fala dos jovens nesse sentido: "por ter sido vítima de violência, ele vem a praticar" (Luiz), e, também em: "uma pessoa fala um negócio com você, ai você num vai, vai querer revidar" (Paulo). Isso pode ser justificado pelas questões de masculinidade que geram a necessidade de comprovação da virilidade por meio de força física, valentia, enfrentamento de perigos e brigas. Com isso, aumentam-se os riscos de sofrerem ou praticarem violência (Milani, 1999). Além do mais, o ciclo é vicioso: quem já ameaçou, acabou agredindo, e quem testemunhou assumiu algumas vezes o papel de algoz. No Distrito Federal (DF), mais da metade dos jovens entre 18 e 24 anos que admitiram agredir conhecidos já foram vítimas de agressão (Grupo Caixa Seguros, 2006).

Outro determinante da violência destacado pelos participantes é que o jovem que não tem nada para fazer comete violência: “. . . porque num tem o que fazer aí fica na rua, sem fazer nada, aí acho que gera violência" (José). A violência se relaciona à forma como as desigualdades sociais e a negação do direito ao acesso a bens e equipamentos (lazer, esporte e cultura) operam nas especificidades de cada grupo social, e assim, podem desencadear comportamentos violentos (Abramovay et al., 2002). Ou seja, isso não estabelece uma relação causal direta: por não ter o que fazer o sujeito cometerá violência. Por outro lado, as condições de vulnerabilidade, em específico, o não acesso a equipamentos de lazer, esporte e cultura, podem resultar em violência por parte do jovem que não acessa esses serviços. Entretanto, vai depender de como essas condições reverberam nesse jovem. Cabe destacar, também, que a violência não é consequência direta da pobreza.

A impulsividade foi mais um dos elementos, trazidos pelos jovens, que pode desencadear comportamentos violentos. Segundo os entrevistados, a juventude é uma fase em que se quer fazer tudo e se age por impulso, assim, seria mais uma explicação para a ocorrência da violência nessa fase geracional, como em: "agindo assim sem pensar, impulsivamente" (Sandra), e, “. . . eu poderia ter feito isso, praticado aquilo, porque a gente tem um repente, num pensa, a pes- 
soa num pensa ai comete o ato" (Maria).

Conforme os entrevistados, as condições socioeconômicas também foram apontadas como desencadeadoras da violência. $\mathrm{O}$ que se verifica no trecho: "acho que através da moradia também, onde a gente mora. Acho que o pessoal vai influenciando o adolescente a fazer. . . porque a família num tinha como manter eles, ai eles achavam que fazendo assalto ia conseguir" (José). Ainda em relação ao contexto de desenvolvimento dos jovens, o não acesso à educação e problemas familiares foram mencionados: "não há uma boa educação, às vezes a pobreza também, falta de conhecimento e às vezes problemas familiar, leva tudo a isso" (Clara).

No caso da educação, como consta na pesquisa Fatores determinantes da violência interpessoal entre jovens no DF (Grupo Caixa Seguros, 2006), quanto maior a escolaridade de uma pessoa, menor a chance de ela vir a agredir alguém. Assim, para concluir os ensinos fundamental e médio, um adolescente leva em média onze anos na sala de aula e cada ano passado diminui em $1,1 \%$ as chances de um jovem entre 18 e 24 anos praticar um ato de violência, ficando $12,1 \%$ menos propenso a esse tipo de atitude. Ao cursar uma faculdade com quatro anos de duração, a porcentagem será de $16,5 \%$, e, assim sucessivamente. Portanto, de acordo com esse dado, o conhecimento reduz a violência (Grupo Caixa Seguros, 2006). Ou seja, os anos de estudo impactam positivamente na diminuição das taxas de violência interpessoal, e, em contrapartida, a reprovação a aumenta. Vale comentar, entretanto, que esses dados representam apenas uma vertente para se olhar o fenômeno, e, embora a educação tenha efeitos positivos sobre a redução da violência, deve-se lembrar da multicausalidade desse complexo fenômeno.

Associado à educação, tem-se o respeito, recorrentemente mencionado como fator determinante da violência. De acordo com o que Lopes et al. (2008) comentam, o respeito mútuo implica uma prática especial de troca, em que o indivíduo deve romper com os pressupostos tácitos e quadros compartilhados de mundo para poder dividir histórias e narrativas. No entanto, a falta de interações sociais saudáveis e reciproci- dade podem desencadear conflitos e situações de violência. Em tais situações, muitas vezes, vítima e agressor se confundem em função da estrutura social e subjetividades estarem interagindo e se retroalimentando - o que talvez explique as inúmeras vezes que a falta de respeito fora mencionada pelos entrevistados. Como exemplos das falas dos jovens, podem-se citar as seguintes: "eles briga, hoje num respeita, eles num respeita mais ninguém, num respeita professor, num respeita pai, num respeita mãe, num respeita o próximo, num respeita cidadão. Tudo isso hoje é a falta de respeito" (Sandra), e, "Acho que quando há falta de respeito, vem agressão, vem agressão verbal, agressão fisica. A falta de respeito faz com que a violência se... Tenha progresso" (Luiz).

Enfim, como já foi afirmado, a violência é multideterminada, portanto, não há de se considerar cada um desses fatores isoladamente. É a associação de diversos elementos - socioeconômicos, políticos e culturais -, além da omissão do Estado (no tocante aos seus equipamentos públicos e na oferta dos direitos humanos fundamentais) que deixam os jovens em contexto de vulnerabilidade social (Santos, Oliveira, Paiva, \& Yamamoto, 2012). Ou seja, é o mesmo que Lopes et al. (2008) apontam, ao levantar uma série de fatores que resultam em violência(s): o estado de vulnerabilidade social, a extrema desigualdade, a precariedade de moradia, as características históricas da formação da família nuclear brasileira, a precarização do trabalho levam, muitas vezes, a uma situação de rupturas da participação e da coesão social. O que pode resultar em

crianças e adolescentes em situação de rua, vítimas da exploração do trabalho infantil, da violência doméstica (física, sexual e/ou psicológica), da violência urbana ou mesmo de formas mais ocultas de violência, como a negligência, que os impedem de usufruir seu lugar de sujeito e de cidadão de direitos. (p. 64)

Juventude-Violência. Nesse eixo, buscou-se discutir se os entrevistados identificam alguma relação entre a juventude (ser jovem) e a violência, se eles próprios sofreram e/ou praticaram, se conhecem algum jovem que sofreu ou praticou, 
e, se acham que o jovem sofre mais ou pratica mais a violência. Cabe destacar que embora os participantes tenham respondido, primordialmente, que não há relação entre a juventude e violência, entendeu-se, pelo teor das respostas, que pode ter havido alguma incompreensão acerca dessa questão. Isso se deve ao fato de que os entrevistados pareceram verificar a relação somente quando há a prática pelo jovem, e não consideram que essa relação poderia existir com ele sendo vítima. Como se observa no seguinte trecho: "não, nem todos praticam violência" (Bruna). Ou seja, os entrevistados parecem não reconhecer que se aumentam, significativamente, as possibilidades de na juventude os sujeitos sofrerem violência, em especial, homicídios por armas de fogo.

Pode se verificar no Mapa da Violência de 2013 - quando se faz uma análise da evolução da mortalidade por armas de fogo no período de 1980 a 2010 - que o crescimento da mortalidade entre os jovens (414\%) foi maior quando se compara ao resto da população $(346,5 \%)$. Da mesma maneira, os homicídios juvenis cresceram: na população total o aumento foi de $502,8 \%$, e entre os jovens foi de 591,5\% (Waiselfisz, 2013). Assim, a preocupação gira em torno tanto do jovem enquanto vítima, quanto como autor. Isso se deve, especialmente, porque nessa faixa etária duas em cada três mortes se originam de uma violência, seja através de homicídio, suicídio ou acidente de transporte (Waiselfisz, 2011).

Lopes et al. (2008) corroboram tal ideia ao trazer que é notória a vulnerabilidade em que se encontram adolescentes e jovens, ocupando o imaginário social tanto na condição de vítimas como de vitimizadores. Ou seja, a relação que pode existir entre juventude e violência está relacionada tanto à prática quanto à vitimização do jovem.

Quando se questiona se o jovem sofre mais ou pratica mais a violência, no geral, os entrevistados relataram proximidade com a violência, seja enquanto autores, vítimas ou expectadores. Entretanto, para eles, a prática é a mais frequente, o que corrobora com dados em que os jovens figuram como o segmento social que mais pratica violência (Ferreira et al., 2009). Por outro lado, se contrapõe ao que fora dito anteriormente pelos jovens ao comentarem não existir relação entre a juventude e a violência, principalmente porque essa relação foi considerada em termos de prática pelo jovem. Some-se a esse fato que o jovem não se reconhece enquanto fazendo parte desse processo de violência, especialmente, porque sua fala é direcionada ao jovem em geral, e, por isso, o entrevistado não se inclui nesse contexto, como em: "o jovem ele parte mais pela euforia, a emoção, droga, sempre isso, sempre isso. Ele acha que ele é novo e ele pode fazer tudo" (Pedro).

Em relação ao jovem como vítima e autor, eles relataram conhecer alguém que já sofreu ou praticou violência, inclusive com exemplos de pessoas próximas, como em: "minha própria irmã, ela já matou" (Sandra). No tocante, especificamente, à prática de violência pelos jovens (sem incluir o entrevistado), os exemplos giraram em torno de: furto/roubo, homicídio, assalto e briga, como na fala de uma entrevistada que presenciou um assassinato em praça pública, em que uma garota de 15 anos mata outra jovem: “. . matou, ela meteu uma faquinha aqui, uma faquinha pequenininha como se fosse uma serra, bem aqui na, na garganta dela, a menina morreu na hora" (Maria).

Quanto à condição de jovem como vítima, os exemplos foram: morte, assalto, briga e abuso sexual, como em: "abuso sexual, é, ela foi estuprada com treze anos" (Sandra). Quando o questionamento passa a ser acerca do próprio sujeito, ou seja, se o entrevistado já sofreu ou praticou, eles relataram que sofreram algum tipo de violência, das quais: assalto e briga, ameaça, apanhar do marido, e abuso sexual. Assim, tem-se um exemplo de um entrevistado que comentou que foi "roubado e agredido com pau e pedra por cinco pessoas" (Paulo). E, em relação à prática, obtiveram-se apenas alguns casos de agressão verbal, agressão física como defesa, brigas entre torcidas, e atentado ao patrimônio público, como por exemplo: "Aí nós praticamos a violência. Geralmente entre gangues rivais. Tem máfia e gangue. A gente fazia parte da gangue", e, "a gente sempre praticava, quebrava ônibus" (Pedro). 
Segundo o estudo dos determinantes da violência interpessoal entre jovens do DF (Grupo Caixa Seguros, 2006), os maiores agentes externos de violência contra a juventude são amigos ou conhecidos, a polícia e o próprio parceiro, nesta ordem. A violência tem apenas um endereço: a rua perto de casa, ou seja, bem próximo à família, acontece o maior número de ameaças e agressões físicas (de $40,7 \%$ a $58,1 \%$ ) entre os jovens de 18 e 24 anos.

Enfim, a violência tendo os jovens como vítimas ou agentes está intimamente ligada à condição de vulnerabilidade social destes indivíduos, e, às deficiências no acesso dos jovens aos bens e serviços (educação, lazer, esporte, cultura e trabalho), propiciando a manutenção dessa realidade. Essa situação, aliada às turbulentas condições socioeconômicas de muitos países latino-americanos, ocasiona uma grande tensão entre os jovens, impedindo os processos de integração social e, em algumas situações, fomentando o aumento da violência e da criminalidade (Abramovay et al., 2002).

\section{O Projovem Urbano como Estratégia de Enfrentamento à Violência Juvenil}

Esse último bloco de discussão consiste na análise das possíveis contribuições do programa na relação juventude-violência, a partir da discussão das seguintes categorias: contribuição do Projovem e ações de enfrentamento. Assim, objetivou-se refletir se o PJU de algum modo traz discussões sobre a juventude e violência, como elas acontecem (em termos metodológicos) e de que forma tem contribuído para intervir no binômio juventude-violência, no que diz respeito ao seu enfrentamento.

Antes de se comentar sobre as categorias, faz-se imprescindível conhecer a organização curricular do PJU. O princípio fundamental do Projovem Urbano é a integração entre Formação Básica, Qualificação Profissional e Participação Cidadã. Dessa forma, tais instâncias podem se fortalecer mutuamente, desenvolvendo-se em consonância com as demandas para uma inserção plena, criativa e produtiva na sociedade contemporânea. Nesse sentido, pretende-se superar a situação de exclusão dos jovens, aliar teoria e prática, e, explorar a dimensão educativa do trabalho e da participação cidadã (Salgado, 2008).

O currículo do Projovem Urbano organiza-se como resultado do cruzamento de eixos estruturantes e conteúdos curriculares selecionados. Ambos foram definidos baseando-se nas características do público potencial, nos objetivos e nas diretrizes definidos para o curso. Cada eixo interage com os componentes curriculares, de modo que, mesmo mantendo-se o ponto de vista específico de cada campo do saber, os eixos e os conteúdos abordam aspectos comuns (Salgado, 2008).

Ao total, são seis eixos estruturantes - que funcionam como temas transversais orientando a seleção dos conteúdos e sua organização em tópicos - em torno dos quais se organizam as chamadas unidades formativas as quais devem ser estudadas ao longo dos três ciclos do programa, ou seja, duas unidades por ciclo. As unidades formativas são as seguintes: Unidade Formativa I - Juventude e Cultura; Unidade Formativa II - Juventude e Cidade; Unidade Formativa III Juventude e Trabalho; Unidade Formativa IV Juventude e Comunicação; Unidade Formativa V - Juventude e Tecnologia; e, Unidade Formativa VI - Juventude e Cidadania (Salgado, 2008).

Para cada unidade formativa foram propostos cinco temas integradores: (a) identidade do jovem; (b) os "territórios" da juventude urbana; (c) violência e vida do jovem; (d) juventude e qualidade de vida; e, (e) juventude e responsabilidade ambiental. Os temas se desdobram ao longo do curso, em cada unidade formativa, relacionados ao eixo estruturante (Salgado, 2008). Nas unidades formativas, esses temas integradores relacionados à violência, e, de acordo com o eixo estruturante correspondente, apareceriam da seguinte forma: Unidade formativa I Juventude e Cultura - Sofrer preconceitos e discriminação; Unidade formativa II - Juventude e Cidade - A violência urbana invade o dia-a-dia dos jovens?; Unidade Formativa III - Juventude e Trabalho - A violência e minha situação de trabalho; Unidade Formativa IV - Juventude e Comunicação - Sexualidade e responsabilidade; Unidade Formativa V - Juventude e Tecnologia - A dificuldade de acesso às tecnologias é uma 
violência contra o cidadão; e, Unidade Formativa VI - Juventude e Cidadania - Ser cidadão é ser ético (Salgado, 2008).

No tocante à análise do PJU, na categoria Ações de enfrentamento - descrição de como o programa pode atuar no enfrentamento da violência - foram mencionadas atividades, ações e metodologia utilizadas na sala de aula para trabalhar o tema da violência. Os entrevistados relataram que há, de fato, diálogos sobre violência no programa de aulas e que acontecem através de meios variados: debates, palestras, produção de textos sínteses sobre o assunto, teatros, discussão quando da ocorrência de uma situação de violência, textos nos livros, vídeos, exposições, distribuição de panfletos. Entretanto, tais discussões não estão ligadas a nenhuma matéria específica. E, em geral, a turma se mostra interessada na discussão, embora alguns prefiram não se colocar.

Quanto à categoria Contribuição do Projovem - como o programa pode contribuir na temática da violência juvenil - os participantes relataram que o programa pode ajudar no enfrentamento à violência em seu bairro, na medida em que essa discussão (através dos professores) chega a quem tem interesse. Como eles próprios comentaram, as orientações, conselhos e conversas "são muito importante pra algumas pessoas abrirem a mente" (Luiz) e "É, mostrando a forma de combater a violência, que eles mostram de todas as formas, né? E, ensinando que a maneira de tudo é o respeito" (Sandra).

Além disso, foi comentado que estar no Projovem à noite também é um fator importante "porque é um horário que a gente tá aqui e acho que é a hora que acontece mais violência é à noite, essa hora da noite. Tem muitos jovens ai sem fazer nada e fica na rua" (José). Ou seja, conforme os jovens, o fato de estarem no Projovem, em si, já representa estar fazendo algo de "útil". Portanto percebe-se um discurso que se baseia na concepção de que a "simples" ocupação pode prevenir ou evitar a ocorrência de violência.

A partir dessas categorias e da análise da estrutura curricular do PJU, percebe-se que, de fato, a temática da violência tem um espaço específico dentro do programa (sendo um dos temas integradores do eixo estruturante). No entanto, parece que a discussão não ocorre de forma sistematizada, inclusive, na fala dos jovens foi dito que ela ocorre quando acontece um ato de violência, por exemplo. Além disso, embora esteja na estrutura curricular, não é relatado pelos jovens que ela aparece em cada disciplina (como deveria ocorrer, até porque se pretende uma abordagem interdisciplinar), mas que ocorre eventualmente e não em um componente curricular específico, embora tenham mencionado a Participação Cidadã como a disciplina em que ela ocorre com maior frequência. Portanto, infere-se que a discussão sobre violência dentro do PJU se mostra importante para esses jovens e de fato pode propiciar mudanças na medida em que eles se sensibilizam para sua importância, embora ainda apareça de maneira incipiente. Nesse aspecto, deve-se refletir sobre o papel das políticas públicas e, em especial, do PJU no enfrentamento à violência (embora não corresponda ao seu objetivo principal) e na promoção de uma cultura de paz na região em que os núcleos se localizam, criando redes de proteção que propiciem a construção de novas relações e formas de sociabilidade.

\section{Considerações Finais}

Diante da pesquisa realizada e das considerações empreendidas (corroboradas por tantos outros estudos que atestam a condição de vulnerabilidade da população jovem) atesta-se a necessidade de continuidade de investigações sobre políticas públicas voltadas a juventude que visam garantir os direitos desse público. Em suma, percebe-se que os recursos à disposição do Estado são insuficientes para, sozinhos, superarem as condições de vulnerabilidade e suas consequências para os jovens, e, mais ainda, no tocante à violência. Portanto, pode-se imaginar quanto o efeito das discussões sobre violência no programa poderia ser potencializado se houvesse um foco maior ou se existissem uma estrutura metodológica que atraísse ainda mais os jovens em programas como o Projovem Urbano.

Quando se pensa na efetivação e avaliação das políticas públicas para as juventudes, tem-se 
que considerar as mudanças que poderão acontecer nas trajetórias de vida dos jovens, especialmente, no sentido de maior autonomia e emancipação. Assim, deve permitir que eles consigam não somente uma "melhor condição de vida", mas que possam problematizar suas realidades, na busca de uma maior conscientização política. Portanto, que se garanta o entendimento de que a política pública, por si só, não é garantidora de transformação na vida do público ao qual se destina, ou seja, ela não é capaz de, isoladamente, provocar mudanças efetivas nas condições de vida de seu público alvo, embora possa gerar algumas reversões de trajetórias.

Nesse sentido, o estudo tem grande contribuição ao lançar mão de uma pesquisa que torna o jovem usuário do Projovem Urbano o porta-voz na discussão e reflexão da problemática da violência - que se faz tão presente nessa categoria geracional pelos motivos já explicitados ao longo do texto. Dessa forma, a pesquisa foi de grande valia para embasar, também, estudos futuros que busquem entender a violência e suas possíveis relações com a juventude a partir da perspectiva do jovem que acessa uma política pública que, em tese, deveria contribuir para minimizar os efeitos da questão social advinda do modo de produção capitalista - especialmente porque há uma escassez de estudos nesse sentido, e, quando tem, se destinam a investigar a percepção dos jovens sobre a violência em contextos específicos, como: violência doméstica (Cardoso, Silva, Carrilho, \& Neves, 2005), nos meios de comunicação (Groebel, 1998) e violência nas escolas (Ribolla \& Fiamenghi, 2007). Por outro lado e de forma mais ampla, tem-se estudos que relacionam, apenas, a percepção sobre a violência às questões socioeconômicas e/ou condições de vulnerabilidades sociais (Cocco \& Lopes, 2010).

Cabe destacar que não foi o intuito fazer uma avaliação do programa e com isso analisar se o Projovem Urbano, e, especificamente, o núcleo visitado para a realização da pesquisa, está cumprindo com o que se destina, mas, dar subsídios iniciais para problematizar os efeitos das ações até então empreendidas, buscando estimular estudos que possam embasar esse processo de avaliação, principalmente por existir uma enorme evasão de alunos. Sem alunos, não há como ser feito um trabalho de qualidade e, daqueles que vão para as aulas, apenas alguns se interessam. De fato, devem ser revistas as metodologias empreendidas em associação com a pesquisa dos motivos que levam esses alunos a deixarem de frequentar o núcleo do Projovem Urbano.

Ademais, o estudo poderia ser realizado em mais núcleos, com uma maior equipe, para ter-se um diagnóstico da percepção da violência para os jovens que acessam o PJU. Vale salientar que dificuldades estiveram presentes, como: não haver aula no dia da entrevista e por isso nenhum aluno comparecer à escola; não ter salas apropriadas (com o mínimo de barulho, sem interferência de pessoas, por exemplo); mudança de gestão que fez com que núcleos desaparecessem, e, por isso, não foi possível dar um retorno ao núcleo onde a pesquisa ocorreu. Além do mais, embora não tenha havido devolução dos resultados à escola que foi sede do núcleo e nem aos jovens que participaram, espera-se que esse artigo cumpra o papel de socializar os achados. Bem como, espera-se que chegue até os gestores do programa, uma vez que isso não foi realizado pelas pesquisadoras, em função dos limites temporais e as dificuldades de gestão na cidade.

Diante do quadro exposto no artigo, fica clara e urgente a necessidade de se romper com a cultura da violência, tão presente e legitimada em nossa sociedade, e, oferecer à juventude outros recursos e possibilidades, para que esse segmento social possa experimentar sua inserção no mundo, tendo os seus direitos efetivados e assegurados.

\section{Referências}

Abramovay, M., Castro, M. G., Pinheiro, L. C., Lima, F. S., \& Martinelli, C. C. (2002). Juventude, violência e vulnerabilidade social na América Latina: Desafios para politicas públicas. Brasília, DF: Organização das Nações Unidas para a Educação, a Ciência e a Cultura. Recuperado em unesdoc.unesco.org/ images/0012/001271/127138por.pdf

Aquino, L. M. C. (2009). Introdução: A juventude como foco das políticas públicas. In J. A. 
Castro, L. M. C. Aquino, \& C. C. Andrade (Eds.), Juventude e políticas sociais no Brasil (pp. 23-39). Brasília, DF: Instituto de Pesquisa Econômica Aplicada.

Cardoso, A., Silva, M. J., Carrilho, P., \& Neves, V. (2005). Principais percepções dos jovens do Concelho de Matosinhos sobre violência doméstica. Lisboa, Portugal: Centro de Estudos para a Intervenção Social. Recuperado em 26 de março, 2014, de http:// www.cesis.org/admin/modulo_news/ficheiros_noticias/20130306110148-1estudoprincipais_percepcoes_dos_jovens_do_concelho_de matosinhos_sobre_violencia_domestica.pdf

Cocco, M., \& Lopes, M. J. M. (2010). Violência entre jovens: Dinâmicas sociais e situações de vulnerabilidade. Revista Gaúcha de Enfermagem, 31, 151-159. Recuperado em http://www.scielo.br/ pdf/rgenf/v31n1/a21v31n1.pdf

Fachinetto, R. F. (2010). Juventude e violência: Onde fica o jovem numa sociedade "sem lugares?" In M. G. B. Almeida (Ed.), A violência na sociedade contemporânea (pp. 60-72). Porto Alegre, RS: Editora da Pontifícia Universidade Católica do Rio Grande do Sul.

Ferreira, H., Fontoura, N. O., Aquino, L., \& Campos, A. G. (2009). Juventude e políticas de segurança pública no Brasil. In J. A. Castro, L. M. C. Aquino, \& C. C. Andrade (Eds.), Juventude e políticas sociais no Brasil (pp. 193-219). Brasília, DF: Instituto de Pesquisa Econômica Aplicada.

Gonçalves, H. S. (2003). Sentidos da violência. In H. S. Gonçalves (Ed.), Infância e violência no Brasil. Rio de Janeiro, RJ: Vau.

Groebel, J. (1998). Percepção dos jovens sobre a violência nos meios de comunicação de massa. Brasília, DF: Organização das Nações Unidas para a Educação, a Ciência e a Cultura. Recuperado em http://unesdoc.unesco.org/ images/0013/001315/131502por.pdf

Grupo Caixa Seguros. (2006). Fatores determinantes da violência interpessoal entre jovens no $D F$. Brasília, DF: Autor. Recuperado em 10 de julho, 2012, de ftp.cve.saude.sp.gov.br/doc tec/ outros/viole_df.pdf

Instituto Brasileiro de Geografia e Estatística. (2012). Sintese de indicadores sociais: Uma análise das condições de vida da população brasileira. Recuperado em ftp.ibge.gov.br/Indicadores Sociais/Sintese de Indicadores Sociais 2012/ SIS 2012.pdf
Lino, A., De Leon, A., Odas, C., Pistori, E., Valente, J., Ricardo, J., ...Romão, W. (2007). Levante sua bandeira: I Conferência Nacional de Políticas Públicas de Juventude - Documento base. Brasília, DF: Conselho Nacional de Juventude.

Lopes, R. E., Adorno, R. C. F., Malfitano, A. P. S., Takeiti, B. A., Silva, C. R., \& Borba, P. L. O. (2008). Juventude pobre, violência e cidadania. Saúde e Sociedade, 17(3), 63-76. doi:10.1590/ S0104-12902008000300008

Milani, F. M. (1999). Adolescência e violência: Mais uma forma de exclusão. Educar em Revista, 15(1), 101-108.

Minayo, M. C. S., \& Deslandes, S. F. (1998). A complexidade das relações entre drogas, álcool e violência. Caderno de Saúde Pública, 14(1), 3542. doi:10.1590/S0102-311X1998000100011

Ministério do Planejamento, Orçamento e Gestão. (2011). Plano Plurianual (PPA) 2012-2015: Projeto de lei. Brasília, DF: Autor. Recuperado em 26 de setembro, 2011, de www.planejamento.gov.br

Novaes, R. (2007). Políticas de juventude no Brasil: Continuidades e rupturas. In O. Fávero, M. P. Sposito, P. Carrano, \& R. R. Novaes (Eds.), Juventude e contemporaneidade (pp. 253-281). Brasília, DF: Organização das Nações Unidas para a Educação, a Ciência e a Cultura.

Novaes, R. (2009). Prefácio. In J. A. Castro, L. M. C. Aquino, \& C. C. Andrade (Eds.), Juventude e políticas sociais no Brasil (pp. 13-22). Brasília, DF: Instituto de Pesquisa Econômica Aplicada.

Penna, G. O., \& Neto, O. L. M. (2010). Prefácio. In M. F. Westphal \& C. R. Bydlowski (Eds.), Violência e juventude. São Paulo, SP: Hucitec.

Pereira, P. A. P. (2008). Discussões conceituais sobre política social como política pública e direito de cidadania. In J. Boschetti, E. R. Behring, S. N. N. Santos, \& R. C. T. Mioto (Eds.), Politica social no capitalismo: Tendências contemporâneas (Cap. 4). São Paulo, SP: Cortez.

Peres, M. F. T., Ruotti, C., \& Vicentin, D. (2010). Violência: Definição, tipos e representações. In M. F. Westphal \& C. R. Bydlowski (Eds.), Violência e juventude (pp. 40-58). São Paulo, SP: Hucitec.

Rechenberg, L., \& Zagallo, M. (2010). Cultura de paz. Novas abordagens sobre prevenção da violência entre jovens. São Paulo, SP: Instituto Sou da Paz. 
Ribolla, M. B., \& Fiamenghi, G. A., Jr. (2007). Adolescentes na escola: Representações sociais sobre violência. Psicologia Escolar e Educacional, 11(1), 111-121. doi:10.1590/S141385572007000100011. Recuperado em http:// www.scielo.br/pdf/pee/v11n1/v11n1a11.pdf

Salgado, M. U. C. (Ed.). (2008). Manual do educador: Orientações gerais (L. B. Jardim, Rev.). Brasília, DF: Programa Nacional de Inclusão de Jovens - ProJovem Urbano. Recuperado em 25 de outubro, 2011, de www.projovemurbano. gov.br

Salgado, M. U. C., \& Jardim, L. B. (2010). Manual do Educador: Orientações Gerais. Brasília, DF: Programa Nacional de Inclusão de Jovens Projovem Urbano.

Santos, L. I. C. (2013). A relação juventude-trabalho no Projovem Integrado do município de Natal/ $R N$ (Dissertação de mestrado, Universidade Federal do Rio Grande do Norte, Natal, RN, Brasil). Recuperado em http://bdtd.ufrn.br/tde arquivos/1/TDE-2014-02-05T153133Z-5847/ Publico/LuanaICS_DISSERT.pdf

Santos, L. I. C., Oliveira, A. M., Paiva, I. L., \& Yamamoto, O. H. (2012). Juventude e violência: Trajetórias de vida e políticas públicas. Estudos e Pesquisas em Psicologia, 12(2), 521-538.

Silva, E. R. A., \& Andrade, C. C. (2009). A política nacional de juventude: Avanços e dificuldades. In J. A. Castro, L. M. C. Aquino, \& C. C. Andrade (Eds.), Juventude e politicas sociais no Brasil (pp. 41-69). Brasília, DF: Instituto de Pesquisa Econômica Aplicada.
Sposito, M. P. (2003). Os jovens no Brasil: Desigualdades multiplicadas e novas demandas políticas. São Paulo, SP: Ação Educativa.

Sposito, M. P., \& Carrano, P. C. R. (2003). Juventude e políticas públicas no Brasil. Revista Brasileira de Educação, 24, 16-39. doi:10.1590/ S1413-24782003000300003

Trinidad, A., Carreiro, V., \& Soriano, R. (2006). Teoría fundamentada "Grounded Theory". La construcción de la teoría a través del análisis interpretacional. Madrid, España: Centro de Investigaciones Sociológicas.

Waiselfisz, J. J. (2011). Mapa da violência 2011: Os jovens do Brasil. São Paulo, SP: Instituto Sangari.

Waiselfisz, J. J. (2013). Mapa da violência 2013: Mortes matadas por armas de fogo. Rio de Janeiro, RJ: Centro Brasileiro de Estudos Latino-americanos.
Recebido: 09/07/2013

$1^{a}$ revisão: $28 / 04 / 2014$

$2^{a}$ revisão: $23 / 05 / 2014$ Aceite final: 28/05/2014 